\title{
Jacques-Olivier Boudon, Les habits neufs de Napoléon
}

\author{
Cyril Triolaire
}

\section{(2) OpenEdition \\ Journals}

Édition électronique

URL : https://journals.openedition.org/ahrf/11915

DOI : 10.4000/ahrf.11915

ISSN : 1952-403X

Éditeur :

Armand Colin, Société des études robespierristes

Édition imprimée

Date de publication : 1 décembre 2010

Pagination : 195-197

ISBN : 978-2-200-92634-2

ISSN : 0003-4436

Référence électronique

Cyril Triolaire, "Jacques-Olivier Boudon, Les habits neufs de Napoléon », Annales historiques de la Révolution française [En ligne], 362 | octobre-décembre 2010, mis en ligne le 22 mars 2011, consulté le 23 avril 2022. URL : http://journals.openedition.org/ahrf/11915; DOI : https://doi.org/10.4000/ahrf. 11915

Ce document a été généré automatiquement le 23 avril 2022.

Tous droits réservés 


\title{
Jacques-Olivier Boudon, Les habits neufs de Napoléon
}

\author{
Cyril Triolaire
}

\section{RÉFÉRENCE}

Jacques-Olivier Boudon, Les habits neufs de Napoléon, Paris, Bourin Éditeur, 2009, p. 168 , ISBN $978-2-84941-130-8,18 €$

1 Napoléon Bonaparte est-il seulement, dans la conscience collective, cette silhouette, coiffée d'un bicorne, la main droite dans le revers d'une redingote grise ? Celui que les sondages placent souvent sur le podium des personnages historiques préférés des Français n'est-il pas aussi, pour les enfants, ce champignon colérique (Gilles Bachelet, Champignon Bonaparte, Paris, Seuil Jeunesse, 2005), pour les acheteurs d'une nouvelle Citroën, celui qui vante la vitesse du dernier bolide de la gamme, ou pour l'amateur d'actualités politiques, celui sous les traits duquel le plus médiatique des présidents ne cesse d'apparaître sur les présentoirs des libraires? Napoléon aurait aujourd'hui troqué son uniforme militaire ou son manteau de sacre contre des habits neufs; et ce sont bien ces nouveaux costumes que Jacques-Olivier Boudon propose à son lecteur d'enfiler, de quitter et de repasser. Alors même que Napoléon fait pleinement partie de notre environnement mémoriel, le spécialiste, président de l'Institut Napoléon et titulaire de la chaire d'Histoire de la Révolution et de l'Empire à la Sorbonne, rappelle l'atonie commémorative dont semble frappée la France en ces temps de bicentenaires répétés. Dès lors que professeurs, journalistes ou responsables politiques évoquent Napoléon, un profond malaise survient, au point que certains préfèrent en taire le souvenir, au risque même de toucher «le fond de la honte et du ridicule", pour emprunter à l'incompréhension matinée de stupéfaction de Pierre Nora (tribune, Le Monde, décembre 2005). Sans chercher à saisir aussi précisément que Sudhir Hazareesingh ( $L a$ légende de Napoléon, Paris, Tallandier, 2004) ou qu'Annie Jourdan (Mythes et légendes de Napoléon, Paris, Privat, 2004) comment s'est élaboré le mythe napoléonien, au fil du temps, Jacques-Olivier Boudon se propose, dans un court essai (168 pages), grand public 
et voisinant parfois avec le catalogage, de comprendre pourquoi un homme et une époque autant chéris des Français, des médias et aussi fréquemment mis à la Une politique ces dernières années n'ont-ils pas eu droit finalement à tous les égards de la Nation, aux temps pressentis de la commémoration.

2 À la différence de 1789, perçue comme l'année fondatrice de la France moderne, invitant naturellement au consensus national, 1804, 1805, 1806 ne donnèrent lieu à aucun élan cérémoniel que les souvenirs d'Austerlitz, d'léna ou même du couronnement auraient pu appeler. Tout juste l'État dépêchait-il une délégation et une ministre de la Défense en République Tchèque pour voir 30000 figurants s'élancer sur le champ de Slavkov, quand le chef du gouvernement boudait le confidentiel rendez-vous de la place Vendôme et le cardinal Lustiger renvoyait les nostalgiques du sacre à la Madeleine. Si le bicentenaire de la naissance de l'empereur séduisit bien de Gaulle et inspira Pompidou à Ajaccio, à un moment où exalter Napoléon revenait à défendre la faculté de la France à conserver son indépendance et à en imposer « une certaine idée " au dehors, les trente années qui suivirent furent peu propices à en raviver le souvenir. Pourtant, que le pays parcourut du chemin depuis les premiers coups d'éclat politiques du jeune Bonaparte corrézien, républicain convaincu et peu séduit par Napoléon, lancé à l'assaut du RPR et de la ville de Paris, et le second séjour élyséen du président Jacques Chirac et de son éminence grise villepiniste passionnée, elle, par l'empereur. À l'heure manquée des commémorations, Jacques-Olivier Boudon rappelle très justement comment la république s'est construite contre l'empire alors même que les années consulaires et impériales ont été essentielles dans la fondation des institutions modernes de la France. Aussi, tandis que les moments forts du Consulat et de l'Empire étaient sciemment oubliés en hauts lieux, le Comité aux célébrations nationales mit lui un soin particulier à rendre honneur aux créations civiles, au Sénat, au Conseil d'État, au Code Civil, à l'Inspection Générale ou aux préfets. Comme si la France contemporaine n'arrivait pas à assumer tout son passé napoléonien, comme si, en cette époque de repentance exacerbée, de lutte des mémoires et d'« ingérence scolaire » des politiques, la France ne pouvait se résoudre à envisager sereinement sa propre histoire. Aussi Jacques-Olivier Boudon montre-t-il avec justesse combien nos voisins surent saisir, eux, le moment du bicentenaire pour promouvoir une Histoire européenne partagée, souligner le rôle de l'époque napoléonienne dans l'affirmation des identités nationales et la construction d'États modernes. Qu'il évoque les manifestations italiennes, suisses, espagnoles, tchèques ou slovaques, organisées durant les cinq dernières années, ou qu'il pointe le "paradoxe d'Iéna" du couple franco-allemand, l'auteur rend habilement moins pesant le silence français à l'heure des commémorations.

3 Car les Français semblent, eux, attachés au souvenir napoléonien; et l'auteur d'essayer alors de comprendre comment s'exprime aujourd'hui cette légende. En cette période de crise, marquée par la quête d'un homme providentiel - davantage encore accrue depuis l'élection présidentielle américaine de 2008 -, Napoléon - tout comme de Gaulle - est, dans les esprits, à la fois ce chef de guerre, qui fait triompher la France, et ce magistrat, qui la refonde ; l'un et l'autre « incarnent une forme d'unanimité nationale qui séduit finalement l'opinion » (p.59). Si le mythe perdure, c'est aussi parce qu'il est entretenu par certains, par-delà un système scolaire qui, devant la progression des études de longue durée, l'affirmation d'une histoire des civilisations ainsi que la dépréciation d'un apprentissage de la chronologie, ne réserve plus qu'une place restreinte au 
Consulat et à l'Empire et en consacre souvent exclusivement les aspects " positifs ». En dehors des murs de l'école de la République, nombreux sont pourtant les lieux, les temps et les acteurs de ce souvenir napoléonien. La reconstitution est assurément l'une des composantes essentielle de la survie de ce mythe, qu'elle soit réelle (sur les lieux mêmes des grandes batailles - et fréquemment menée par les passionnés d'uniformologie) ou virtuelle (sur le champ reconstitué de la maquette, occupé par des figures peintes, autant que sur l'écran de l'ordinateur de l'amateur de jeux vidéos). Celle-ci passe aussi par la mise en valeur du "patrimoine impérial» dans l'univers visuel des Français (des arcs et fontaines parisiens en passant par les rares statues provinciales en son honneur) ou l'organisation régulière de grandes expositions (sur le modèle de celles de Vivan Denon au Louvre ou du mobilier Empire aux Arts décoratifs), en l'absence de musée Napoléon proprement dit. Complaisamment et un peu trop longuement, Jacques-Olivier Boudon souligne enfin le rôle joué par les associations napoléoniennes, au premier rang desquelles, sans surprise, le Souvenir napoléonien, la Fondation Napoléon et l'Institut Napoléon.

4 Largement fondé sur la construction des images, le mythe napoléonien est ensuite apprécié dans son univers médiatique le plus contemporain, ou au moins celui du siècle dernier. L'auteur livre des pages plaisantes où se retrouvera aussi bien le spécialiste que le simple curieux. Faisant très fréquemment le grand écart et offrant à lire une sélection inévitablement réductrice, Jacques-Olivier Boudon propose de suivre Napoléon au cinéma, rappelant qu'il inspira aussi bien au fil des ans Promio, Lumière et Gaumont que Gance, Vidor, Bondartchouk et plus récemment Virzi ou de Caunes. Tandis que Guitry ou Barrault lui donnent corps dans les salles obscures, d'autres acteurs, plus populaires, l'incarnent à la télévision, dans des fresques à épisodes grand public. Car Napoléon n'est plus au sommaire des émissions-débats sacrifiées sur l'autel du divertissement télévisuel, il s'est mué au fil des ans en une figure marketing chérie des publicitaires, vantant aussi bien en France qu'à l'étranger les mérites d'un cognac, d'un GPS ou d'une ligne de train à très grande vitesse. Il redevient même un véritable objet de spectacle et réapparaît aujourd'hui au théâtre, signe de la fascination qu'il continue finalement d'exercer sur les créateurs. Les auteurs aussi continuent de l'affectionner, que de leur inspiration naissent, hier, des œuvres majeures à ranger au panthéon littéraire - Dumas, Balzac, Tolstoï, Stendhal -, et, aujourd'hui, des histoires romanesques populaires - Max Gallo -, des romans policiers - Caratini, Cabasson, Bornet - et des pensums journalistiques - Joffrin, Giesbert, Jamet. De toute part l'édition s'empare du mythe. Et Jacques-Olivier Boudon de lister alors les grandes maisons éditoriales œuvrant à la publication des travaux sur l'empire, dans une tirade quelque peu publicitaire, et de bâcler enfin ses lignes sur la présence de Napoléon sur Internet, là où la présentation d'une véritable galerie numérique et un examen critique étaient davantage attendus que les résultats d'une simple recherche sur Google.

L'auteur livre ses pages les plus intéressantes dans un quatrième et dernier chapitre tout aussi politique finalement que le premier, décortiquant la place de Napoléon dans le milieu et le discours politiques les plus immédiats. Ses derniers descendants ayant manifesté leur attachement à la république et l'héritage noir de l'empire rendant toujours mal à l'aise certains, Napoléon n'a plus réellement la cote en politique (p. 129). Très rares sont désormais les allusions et les soutiens. Jamais pourtant paradoxalement? - au plus haut sommet de l'État, passions et comparaisons ne paraissent avoir été aussi manifestes et soignées que ces dernières années. L'affrontement politique fratricide entre le chef du gouvernement, de Villepin, et le 
ministre-candidat de l'hôtel Beauvau, Sarkozy, puis, ses rebondissements entre l'hyper président et le banni des cabinets élyséens n'auraient pas été les mêmes sans leur toile de fond napoléonienne. L'historien décrit ainsi justement l'étrange balai se jouant entre l'ancien pensionnaire de Matignon passionné par l'épopée impériale, soucieux de la restauration des lieux français à Sainte-Hélène, qui s'interroge sur la question de la légitimité et du déclin du pouvoir dans plusieurs ouvrages finalement tout aussi historiques qu'introspectifs, et le prétendant neuilléen au fauteuil présidentiel perçant incessamment sous les traits du général des armées de la république franchissant les Alpes au col du grand Saint-Bernard. L'énergie déployée, la politique d'ouverture menée et la volonté d'en appeler au peuple comme la proximité avec la Corse ou la saga familiale quasi perpétuelle des premiers jours ne suffisent pourtant pas à confondre Sarkozy et Napoléon. Les images très napoléoniennes du sauveur, du réformateur et du parfait communicant collent pourtant encore dans l'esprit de nombreux Français avec celle de l'homme de la rupture, hyper-médiatique, sans cesse cultivée par l'actuel président.

Ce livre s'adresse prioritairement au grand public sensible à l'épopée napoléonienne et désireux de mieux comprendre l'association éditoriale et médiatique SarkozyNapoléon. Mais à finalement vouloir endosser toute la nouvelle garde-robe impériale, l'auteur se limite parfois à un simple inventaire sans prendre soin de s'intéresser à tous les accessoires et en laissant dans leurs cartons certains vêtements qui auraient eux aussi mérité d'être mis en rayon. Si nos voisins européens ont ainsi plus sereinement su fêter les derniers bicentenaires impériaux, la dérision avec laquelle ils savent assumer "leur» héritage napoléonien aurait pu nourrir de savoureux développements (les austères panoplies des "souvenirs" napoléoniens offertes dans les musées parisiens, bellifontain ou briennois tranchent avec les loufoques chopes de bière munichoises ou certaines caricatures de plâtre du musée morave d'Austerliz; les très glorieuses statues équestres de Rouen ou de la Roche-sur-Yon ne partagent pas l'extravagance du Napoléon « enchapeauté » de l'Hlavne namestie de Bratislava). Enfin, si les éditorialistes ne cessent de comparer les fougues d'un Napoléon et d'un Sarkozy, l'historien du temps présent n'aurait-il pas, lui, pu décrypter la riche contre-imagerie populaire née dans les grandes manifestations des trois dernières années et détournant la légende noire de l'empereur aux dépens de l'actuel président? Le sujet est sans aucun doute loin d'être épuisé ; voilà sans doute le meilleur signe de son extrême vitalité.

\section{AUTEURS}

\section{CYRIL TRIOLAIRE}

fr 